Georgia State University

ScholarWorks @ Georgia State University

$1-1-2008$

\title{
Competition Between Auctions
}

\author{
Ernan Haruvy \\ University of Texas at Dallas \\ Peter Popkowski Leszczyc \\ University of Alberta \\ Octavian Carare \\ University of Texas at Dallas \\ James Cox \\ Georgia State University \\ Eric Greenleaf \\ New York University
}

See next page for additional authors

Follow this and additional works at: https://scholarworks.gsu.edu/excen_workingpapers

\section{Recommended Citation}

Haruvy, Ernan; Popkowski Leszczyc, Peter; Carare, Octavian; Cox, James; Greenleaf, Eric; and Jank, Wolfgang, "Competition Between Auctions" (2008). ExCEN Working Papers. 100.

https://scholarworks.gsu.edu/excen_workingpapers/100

This Article is brought to you for free and open access by the Experimental Economics Center at ScholarWorks @ Georgia State University. It has been accepted for inclusion in ExCEN Working Papers by an authorized administrator of ScholarWorks @ Georgia State University. For more information, please contact scholarworks@gsu.edu. 


\section{Authors}

Ernan Haruvy, Peter Popkowski Leszczyc, Octavian Carare, James Cox, Eric Greenleaf, and Wolfgang Jank 


\title{
Competition Between Auctions
}

\author{
Ernan Haruvy, University of Texas at Dallas \\ Peter T. L. Popkowski Leszczyc, University of Alberta \\ Octavian Carare, University of Texas at Dallas \\ James C. Cox, Georgia State University \\ Eric A. Greenleaf, New York University \\ Wolfgang Jank, University of Maryland \\ Sandy Jap, Emory University \\ Young-Hoon Park, Cornell University \\ Michael H. Rothkopf, Pennsylvania State University
}

* This paper is based on the special session at the $7^{\text {th }}$ Triennial Invitational Choice Symposium, at the Wharton School of Business, University of Pennsylvania, June 2007 (co-chaired by the first two authors). 


\title{
Competition Between Auctions
}

\begin{abstract}
Even though auctions are capturing an increasing share of commerce, they are typically treated in the theoretical economics literature as isolated. That is, an auction is typically treated as a single seller facing multiple buyers or as a single buyer facing multiple sellers. In this paper, we review the state of the art of competition between auctions. We consider three different types of competition: competition between auctions, competition between formats, and competition between auctioneers vying for auction traffic. We highlight the newest experimental, statistical and analytical methods in the analysis of competition between auctions.
\end{abstract}

Key words: auctions, bidding, competition, auction formats, auction houses

Auction research is widespread in many fields of business research, social sciences, computer sciences and statistics. These cross-disciplinary approaches to auction research offer fresh angles on issues not addressed previously, such as customer retention, relationship development, platform design, and novel statistical approaches.

One reason for the explosion in research is that auctions are increasingly prevalent in all aspects of commerce, from procurement of materials and services for production and operations to consumer auctions of finished goods. Auctions also have special attraction for government exchanges. Insights from auction research are also being applied to other modes of exchange, including two-sided markets, posted prices and negotiations.

Even though auctions capture an increasing share of commerce, they are typically treated in the economics literature as isolated. That is, an auction is typically treated as a single seller facing multiple buyers or, in the case of procurement auctions, as a single buyer facing multiple sellers. This treatment greatly simplifies the theory, but it limits auction theory to monopoly sellers or monopsony buyers and fails to consider the interface between these auctions and their market contexts or related auctions.

There are two primary reasons for the omission of competition in the auction literature. The first is the lack of tractability. With the addition of competitive considerations, intractability makes auction theory and its insights much less appealing. The second reason is historical. Prior to the advent of the Internet 
in the $1990 \mathrm{~s}^{1}$, consumer auctions were not common but to the extent that they existed (as in art auctions, charity auctions and bankruptcy auctions) auctions were in large part isolated events since it was costly for consumers to search for alternative auctions. Business and government auctions were likewise standalone events. Milgrom (2004) argues that the defining event that changed the auction landscape towards consideration of multiple auction events was the rise of FCC spectrum auctions in the 1990s. Both the Internet, in changing consumer auctions, and the FCC initiative, which produced the massive academic activity on package bidding, happened around the mid 1990s and therefore (with a publication gap) most of the relevant literature is less than 10 years old.

The focus of this review is on works that attempt to rectify the omission of competition in auctions. Our discussion does not assume nor require any knowledge of the broader auction literature, but recent practical overviews are offered by Klemperer (2004) and Milgrom (2004).

We motivate the implication of this omission with two simple and well-known examples. The first example is regarding the usefulness of reserve price—a commitment not to sell below some price-- in improving seller revenue. There is a consensus among the leading auction theorists (Harris and Raviv, 1981; Maskin and Riley, 1984; Milgrom and Weber, 1982; Riley and Samuelson, 1981) that reserve prices raise the seller's revenue, since they induce higher bids by high-value buyers, outweighing the costs of excluding sales to low value bidders. However, now consider two parallel auctions, say on eBay, for near-identical items. One has a high reserve price and the other has no reserve price. Which is more likely to attract the first group of bidders and gain price momentum? The intuitive answer (verified empirically by Haruvy and Popkowski Leszczyc, 2007a) is that initial bidders will at first choose the auction with no reserve price. To the extent that bidders do not switch much between auctions (Haruvy and Popkowski Leszczyc, 2007a), the final price in the auction with no reserve price

\footnotetext{
${ }^{1}$ Milgrom (2004) contends that the defining event that changed the auction landscape towards consideration of multiple auction events was the rise of FCC spectrum auctions in the 1990s. We devote some space to package auctions in this review, but Internet auctions receive more attention here. These two events took place at precisely the same time-so the historical argument remains.
} 
will be higher. This intuitive finding reverses an accepted aspect of auction theory. This contradiction between established theory and simple common sense, one of numerous such contradictions, is a direct result of the omission of competition.

Our second example pertains to the omission of competition between auction houses. Consider the well-known finding by Roth and Ockenfels (2002) regarding sniping in electronic auctions. They found that with hard closing times, more bidders submit last second bids—a practice known as sniping. Thus, in the hard closing format, sellers face reduced revenues relative to a soft closing rule, whithout sniping. The auction house, in this case eBay, stands to lose as well since it collects a percentage of sales. Hence, in a market with a single auction house, the choice is clearly to avoid hard closing rules. Yet, eBay started out facing competition from Amazon and Yahoo, both using soft closing rules and both much bigger financially in terms of user base than eBay at the time. The decision of which closing rule to use had to be made with that in mind and eBay selected the hard closing rule 2 .

We begin with competition between auctions and consider the simplest form: competition between similar items, holding the auctioneer and format constant. Such competition can be between simultaneous auctions for the same item, overlapping auctions, or sequential auctions, and can be between items by the same sellers (section 2.1) or between competing sellers (section 2.2). Finally, we also consider competition between auctions with complementarities and substitutes (section 2.3).

We then extend this discussion to competition between formats, where format differences are defined as narrowly as adding a buy-it-now feature or as broadly as moving from an auction to a posted price or negotiation (see section 3). Recent years have seen new auction formats that did not exist 10 or 20 years ago, when much of the theoretical literature was written. Examples range from new features in online consumer auctions, such as buy-it-now options, to procurement variations, including buyer-

\footnotetext{
${ }^{2}$ The factors that led to eBay dominating the electronic auction market in the United States over its much bigger rivals are numerous and complex. They cannot and should not be reduced to the closing rule decision and we do not wish to do so here. Nevertheless, it is clear that every single format decision (and other strategic decisions) made by eBay had to take into consideration the actions of its competitors, and in this case the format choice served to both differentiate eBay and to create a buzz about sniping. We would also like to emphasize that the implied omission of competition does not affect or detract from the results of Roth and Ockenfels. It only sheds a different light on the interpretation of their findings.
} 
determined auctions — where the buyer determines the winner -- and partial price visibility formats. We also discuss auction format for industrial auctions (section 3.1) and award rules used in these auctions (section 3.1.2).

Lastly, we discuss competition between auction hosts vying for auction traffic (section 4). In such platform competition, network externalities, auction design, customization and other considerations arise that have not been previously considered in the auction literature.

Within each section, we highlight the newest methods in the analysis of competition between auctions. We identify three primary areas of methodological innovation. (1) Experimental. Empirical work on competition between auctions is complicated by imperfect similarities and uncontrolled variations. Large differences in auction features may further complicate isolating particular features to study. One way to overcome such difficulties is through laboratory or field experiments that carefully control irrelevant sources of variation. (2) Statistical. The relationships between price dynamics and final prices in auctions of similar items have to be specified. This requires similarity measures, specification of price dynamics in unevenly-spaced time intervals, specifications of migration behavior between auctions, and the modeling of expectations of future auctions. (3) Analytical. Considerations of alternatives by bidders and of competition by sellers must be incorporated into the theoretical framework.

\section{Competition between Items and Competition between Sellers}

On eBay, it is common to see relatively homogenous items such as popular books and CDs offered in simultaneous and overlapping auctions, as well as sequentially over time. Such auctions can be differentiated by sellers’ reputation (Bajari and Hortaçsu 2004), the duration of the auction (Haruvy and Popkowski Leszczyc 2007a), shipping and terms (Haruvy and Popkowski Leszczyc 2007a), reserve and secret reserve prices (Katkar and Reiley 2006), the buy-it-now option (Chan, Kadiyali and Park, 2006; Park and Bradlow, 2005; Popkowski Leszczyc, Qiu and He 2007; Reynolds and Wooders, 
2007; Matthews and Katzman, 2006), bid increment (Rothkopf and Harstad 1994), and other features. It is important for sellers to understand how various features of their items and the auction format affect their competitive positions as well as buyer sensitivity to prices. Various works have investigated these dimensions of differentiation, and we review some here and others in the section on auction formats.

\subsection{Competition between items}

The "law of one price" has been shown to be violated in online auctions. Sun (2005) for example showed large price dispersion in 3,164 sequential eBay auctions for identical items. In concurrent eBay auctions, Anwar, McMillan and Zheng (2006) find that significant cross-bidding occurs and that bidders switch to lower-priced auctions. Nevertheless, not all bidders switch to lower-priced auctions and significant price dispersion may still occur in concurrent auctions. In a controlled design, Haruvy and Popkowski Leszczyc (2007a) ran concurrent eBay auctions in pairs. Some pairs involved two identical auctions and others involved slight variations between the auctions such as minimum bid, secret reserve and shipping cost, but otherwise keeping the seller, product, description, and starting and ending times identical. They found that roughly $16 \%$ of bidders ever placed a bid in a concurrent auction, and that of these bids, only 58\% were in the lowest price auction. (Random choice would have resulted in 50\% optimization among a pair of choices.) In a different work, Haruvy and Popkowski Leszczyc (2007b) studied choices over pairs of auctions for identical items differing only in the percentage donated to charity. Cross-bidding in these pairs was higher at over $20 \%$, and choice of the lowest price alternative was not much above 50\%. In both of these works, inertia and significant heterogeneity was found on that aspect of behavior as well as on charitable intent in the case of charity auctions. Popkowski Leszczyc and Rothkopf (2007) likewise found evidence for heterogeneity in charitable intent in a pairwise study of charity auctions.

In summary, in a competitive marketplace with multiple simultaneous and overlapping auctions, relatively few bidders migrate across auctions. After entering a specific auction, few bidders switch, 
even though they may be able to obtain a lower price in concurrent auctions for identical products. This has important implications for auction design, including possibilities of inducements for bidders to increase search (Haruvy and Popkowski Leszczyc 2007a). Lin and Jank (2007) further analyze bidder migration by breaking down bidder behavior into types of bidders. Reasons for the migration could be either previously unsatisfied demand (a losing bid) or bargain hunters who hop from one auction to another in search of a good deal. Interestingly, the effect of these different migrating types on the auction outcome is mixed. One effect of migration is learning, as migrating bidders obtain greater experience and adjust their behavior. Another point that has not received much attention in standard auction theory is that of an auction's price dynamics and how the dynamics change over the course of an auction. In order to study the entire auction-path rather than just its endpoints, Wang, et al. (2006) used Functional Data Analysis (FDA), a method which focuses on set of curves, shapes, objects, or, more generally, a set of functional observations. Knowledge of the entire auction-path leads to new and useful concepts such as an auction's velocity or acceleration which allows the researcher to study competition in a dynamic setting. In addition, Hyde, Jank and Shmueli (2006) used FDA to create new data-visualization tools, known as auction rug plots, to study simultaneous auction price processes. Wang, Jank and Shmueli (2007) show that incorporation of an auction's price dynamics can lead to considerable improvements in the accuracy of predictions of interim and final price. Moreover, Bapna, Jank and Shmueli (2006) provide more evidence that dynamics exist and matter. Park and Bradlow (2005) study bidding behavior over the entire sequence of bids by building a comprehensive descriptive model, which models several key components of the bidding process (e.g., whether an auction prompts any bids; if so, who bids, when they bid, and how much they bid).

Jap and Naik (2007) use Kalman filtering estimation techniques to provide a method for forecasting interim and final prices and selecting among dynamic bidding models based on point-bypoint data in reverse auctions. Their approach also aids the buyer's price discovery process. Specifically, given the estimated price distribution from the forecasting model "BidAnalyzer", the 
buyer can determine whether a supplier has bid too aggressively (and faces a winner's curse) or has held back (leaving “money on the table”).

Dynamics in simultaneous or overlapping auctions, where the price dynamics in one auction affect the price dynamics in another auction (e.g., Zeithammer 2006), is considerably more complex and creates new challenges. To date, there has not been much work done on this particular challenge (see Jank and Zhang, 2007, for some preliminary work). A major challenge of modeling concurrent (or simultaneous) auctions is the modeling of (1) a temporal component, consisting of unevenly spaced time-series of closing times of auctions, and (2) a spatial component that reflects the distance between two products in feature space. Jank and Shmueli (2007) proposed a new solution by applying a spatialtemporal model. This model solves the problem of unevenly spaced time-series and includes an overall distance measure for combining all quantitative and qualitative product attributes (similar products lie in close proximity in feature-space). The resulting model is estimated within a semiparametric framework which allows for a flexible estimation of the many unknown functional relationships. Jank and Shmueli (2007) found that temporal price and the effect of similar items both influence final auction price. To model a bidder's willingness to pay in ascending first-price auctions, Chan, Kadiyali, and Park (2007) consider two-dimensional market competition using notebook PC data. They use breadth and depth measures to characterize market competition in online auctions. Chan et al. (2006) also incorporate these measures in examining sellers' decisions about whether and where to set buy-itnow prices. Bradlow and Park (2007) consider a sequence of bids in online auctions with an analogy of record-breaking events. Similar to Chan et al. (2007), they find significant negative effects for bid increments and variances in both market competition measures. This informs both breadth and depth measures and helps bidders better determine bid amounts, reducing the uncertainty in bid increments.

Learning is another dynamic component and can occur either in the course of an auction or in participants' auction use over time (e.g., Wilcox 2000, Roth and Ockenfels 2002). In an analysis of 785 online wholesale automotive first price auctions over a 29 month period, Overby and Jap (2007) find 
that the initial appeal of the online auction for buyers is the reduction of transaction costs (i.e., travel). But over time, buyers leveraged the reduced search costs associated with these mechanisms to source rare vehicles. Similarly, sellers adapt their use of auction mechanisms, increasingly relying over time on online auctions as a means for selling their low condition grade vehicles and physical auctions as the primary channel for their better condition grade vehicles.

\subsection{Competition between sellers}

The typical approach to characterizing the equilibrium bids in standalone auctions is to derive the bids given a bidder's knowledge of the other bidders' value distributions. While some of these problems can be complex, their difficulty pales in comparison to the complexity presented by multiple competing auctions. We begin with the economics methodology developed in recent years to deal with competition between sellers and endogenous entry in auctions.

Much of equilibrium bidding theory for single auctions assumes an exogenously determined number of bidders. Harstad (1990), Levin and Smith (1994) and Cox, Dinkin, and Swarthout (2001) extended the theory to incorporate endogenous determination of the number of competing bidders. Levin and Smith's model assumes an opportunity cost of entry that is the same for all bidders, which leads to a mixed strategy for the entry decision. Cox, Dinkin, and Swarthout's model incorporates individual-specific opportunity costs that support pure strategy equilibrium entry and bid functions.

McAfee (1993) studied a dynamic auction market with many sellers and many buyers. He found that the equilibrium reserve prices posted by sellers were equal to the sellers’ values and therefore efficient. Peters (1997) relaxed McAfee’s assumption of identical sellers and found that in equilibrium sellers offered second-price auctions augmented with reserve prices equal to their costs.

Hernando-Veciana (2005) analyzed seller competition as a multistage game where first sellers commit to their reserve prices, then bidders choose one auction to participate in, and then the auctions 
take place. He showed that it is optimum for sellers to announce reserve prices equal to their costs if the numbers of sellers and bidders were sufficiently large.

McAfee and Vincent (1997) investigated a related problem in which the seller cannot commit not to re-auction an object that was not sold. They found that sequential first- and second-price auctions were revenue equivalent. Similar to the Coasean dynamics from sequential bargaining settings, they found that as the time between auctions went to zero the revenue from the sequence of auctions approached the revenue from a single auction with no reserve price.

A number of theoretical issues concerning competing auctions remain unexplored. It would be interesting to find out, for instance, how competition between sellers is likely to affect platform design. Also of interest is an analysis of the sellers' competitive choice of object quality in competing auctions. Further, since sellers can often choose the number of objects they auction off, it would be important to analyze the competitive choice of objects for sale.

There is some empirical work on sequential auctions. Donald, Paarsch and Robert (2006), for instance, tackle the problem of estimation of the parameters of the distributions of values and of participation costs in sequential auctions. Jofre-Bonet and Pesendorfer (2003) analyze bidding in repeated highway procurement auctions using the first-order conditions for optimality. Carare (2007) uses a model of search to deduce the effect on bids of imposing a stationary reserve price in sequential auctions of identical objects. Using data collected from online auctions, he finds substantial gains in revenue from the imposition of a reserve price.

Most of the theoretical papers discussed above focused on optimal reserve price strategies in markets with competing sellers. The findings of these models generally suggest a single reserve price strategy to be used by all sellers. Empirical analyses conducted by Xie, Elrod and Popkowski Leszczyc (2007) indicate that while sellers tended not to adapt to competitor's strategies, they can be better off by differentiating their strategies. Results of their simulation analyses show optimum reserve price strategies under different competitive market conditions. 
Recent literature has emerged which looks at competition in procurement auctions, where buyers and sellers have non-price preferences over each other. In such competitive settings, the problem can be reduced to a matching problem. Losing bidders migrate to other auctions and the converged outcome can be mapped to a stable outcome where no buyer-seller coalition can block the resulting match (see, e.g., Haruvy and Unver 2007; Dogan, Haruvy and Li 2007).

\subsection{Competition with Complementarities and Substitutes}

Buyers often need to purchase a bundle of complementary goods as opposed to individual unrelated goods. High complementarities create an “exposure problem” as bidders may be hesitant to bid high on items in an efficient bundle if there is a risk of obtaining only part of the bundle.

One approach in the auction literature regarding this observation is to assume a single seller offering multiple bundles of goods. The seller can then design and enforce customized market exchange rules such as various types of combinatorial auctions. Combinatorial auctions are auctions in which bidders can place a bid on a combination ("package”) of items.

Cox, Offerman, Olson, and Schram (2002) experimented with two alternatives for privatizing passenger rail service: (a) competition for the rails; and (b) competition on the rails. This research was concerned with the properties of alternative auction allocation mechanisms that had to compete for political support. In the on-the-rails scenario, competing train operators bid on rights to use route/time slots in a laboratory version of a rail network with multiple route/time slots with passenger demand complementarities and substitutabilities. Rights were allocated with a high-bid, multi-round combinatorial auction in which operating companies could bid on any feasible package of route/time slots they selected. The uncertain value of any winning bid was determined by solution of a system of network demand equations with a fixed point algorithm. In the for-the-rails scenario, operating companies bid on passenger fare price indexes for pre-specified minimum route/time slot schedules with the low bidders being awarded limited-term regional monopolies. The two policy alternatives 
involving different auction formats were evaluated by the authors with several criteria; the for-the-rails alternative with fare index bidding won the political competition at the Ministry.

A variety of industries have used combinatorial auctions, including truckload transportation, bus routes, industrial procurement, and most famously, FCC spectrum auctions (Cramton et al. 2006). In spectrum auctions, different bandwidths can serve as substitutes or as complements for different firms. Package bidding is intended to minimize the exposure problem, although it may create a "threshold problem” if efficient combinations of small bidders are unable to coordinate a response to an aggressive package bid by a large bidder.

Laboratory experiments run by Goeree and Holt (2007) compared simultaneous, multi-round auctions and simultaneous multi-round auctions with package bidding. They find that with high complementarities, package bidding raises efficiency, but with low complementarities, it reduces efficiency. Using tiered package bidding as suggested by Rothkopf et al. (1998) improves efficiency relative to other methods by eliminating problems bidders had in "fitting" complex bids together. From the seller's perspective, combinatorial auctions involve a complex integer programming problem to determine the revenue maximizing set of non-conflicting bids and can be computationally challenging. Rothkopf et al. (1998) identified several different structures of combinatorial bids for which computational tractability was demonstrated and others for which tractability could not be guaranteed. For example, they showed that limiting allowable bids to singletons, doubletons, and some larger sets allowed for computational tractability. Pekec and Rothkopf (2004) discuss opportunities for mitigating computational problems at four points in the auction: before bids are submitted, at the time bids are submitted, following bid submission, and after the announcement of tentative winning bids.

From the buyer's perspective, the computation is more complex but very interesting potential strategies emerge. Jump bidding is a promising direction (Milgrom, 2007). Jump bidding can solve the exposure problem by resolving the outcome for one item early on. That is, by putting a bid high enough to eliminate some other bidders from that item, a bidder may be able to obtain other items cheaply (as 
bidders that are now sure they cannot win the first item, they may value the other items less due to loss of potential complementarities). Hence, a set of simultaneous auctions with complementarities can be transformed to a set of sequential auctions with the use of jump bidding, which in turn changes the information structure.

Combinatorial auctions have two features that greatly affect their design: computational complexity of winner determination and opportunities for cooperation among competitors. Dealing with these two features forces trade-offs between desirable auction properties such as allocative efficiency, revenue maximization, low transaction costs, fairness, failure freeness, and scalability. Computational complexity can be dealt with algorithmically by relegating the computational burden to bidders, by maintaining fairness in the face of computational limitations, and by limiting biddable combinations and the use of combinatorial bids (Pekec and Rothkopf, 2003).

Zeng, Cox and Dror (2007) argue that the single seller combinatorial auctions apply only to very specialized items. The trading rules are too complicated for most sellers to apply and individual sellers typically do not offer the entire range of goods for a consumer’s required bundle. From a buyer’s perspective, participating in a combinatorial auction requires significant computational expertise not possessed by most buyers. Another approach that is likely more applicable in general settings is to consider multiple sellers. Zeng, Cox and Dror (2007) develop models of bidding activities across multiple existing markets that sell single items to satisfy bundled and combinatorial needs. They find optimal bidding functions and outline optimal participation choices through integer programming.

One difficulty regarding the treatment of complementary auctions by different sellers is that such auctions are likely to have an empty core. This means that a coalition of buyers and sellers can block the outcome of such auctions by contracting outside the auctions. This could result, for example, in unraveling, as manifested in contracts being finalized prior to the auctions.

\section{Competition between Formats, Mechanisms, and Institutions}


As auctions become a mainstream mode of exchange, sellers in forward auctions and buyers in reverse auctions demand and receive more choices of formats. For example, a seller on eBay can choose among many auction features. Some of the more researched features are the reserve price and secret reserve price (Katkar and Reiley 2006), the buy-it-now option (Chan et al. 2006; Park and Bradlow, 2005; Popkowski Leszczyc et al. 2007), hard and soft ending (Roth and Ockenfels, 2002), and the posted price (Wang, 1993). Buyers in procurement auctions can choose to combine auctions with negotiations (Engelbrecht-Wiggans and Katok, 2006), can choose between price and various scoring rules for winner determination (Che, 1993), or can choose new formats that limit price visibility (and presumably limit opportunism), such as rank-based auctions or auctions where only the lowest price is displayed. Sometimes, these auction formats compete indirectly, as participants show preference for one over the other. Other times, the various formats compete directly as in cases where eBay auctions with different formats are running simultaneously.

Ivanova-Stenzel and Salmon (2004) examined bidder preferences between alternative auction institutions. In their experimental investigation, bidders could choose between an ascending auction and a sealed bid auction with various entry prices. The number of bidders in each auction format was held at two. Varying the entry prices allowed the researchers to determine not only which auction institution was preferred but also the monetary value of that preference. They found strong preferences for the ascending institution with bidders choosing it overwhelmingly when entry prices for the two auctions are the same. When the entry prices of the two auctions differ, many subjects were willing to pay more to enter the ascending auction.

\subsection{Industrial Auction Formats}

Competition between formats is evolving especially rapidly in the business-to-business world where format choice can be worth billions of dollars in savings. New and innovative format choices appear faster than theorists can grapple with. The main variables under consideration in format choice 
for procurement auctions appear to be final prices and relationship variables. By their very nature, procurement auctions involve repeated interaction, long-term dynamics, and considerable economic stakes. In these contexts, the relationship between buyers and their supply base can have considerable impact on bidding strategies and can be impacted by auction dynamics. As such, procurement auctions cannot be viewed as standalone auctions the way consumer auctions have often been analyzed.

\subsubsection{Award Rules}

Unlike consumer auctions, procurement auctions often utilize "buyer-determined” award rules, meaning that while the auction provides a format for price competition, the buyer ultimately selects the final winner because of non-price considerations such as product quality, supplier responsiveness, and other idiosyncratic aspects of the buyer’s needs and circumstances (Jap 2002; Rangan 1998). ${ }^{3}$ For example, Engelbrecht-Wiggans, Haruvy and Katok (2007) compared buyer-determined and pricedetermined auction formats experimentally and found that for a small number of bidders, price-based auction formats may provide greater buyer surplus but that buyer-determined auctions provided greater buyer surplus for a sufficiently large number of bidders. Haruvy and Katok (2007) compared dynamic and sealed bid auctions with different information structures. They found that sealed bid auctions provided greater buyer surplus, and that more transparency to bidders resulted in less buyer surplus.

However, the use of buyer-determined award rules can be detrimental to the buyer-supplier relationship (Jap 2003; Jap and Haruvy, 2007). Jap (2007) finds that full price visibility English (reverse) auctions raise suppliers' beliefs that the buyer is using such auctions to opportunistically gain price concessions. This has resulted in growing interest, by both the marketplace and academics, in the use of partial price visibility formats. Using data from over 14,000 auctions, Millet et al. (2004) found that revealing the lowest bid and bid rank to suppliers can yield greater price savings than less visible formats (i.e., low bid only or rank bid only). Jap (2007) shows that partial price visible formats (e.g.,

\footnotetext{
${ }^{3}$ Many of these attributes may be difficult to express quantitatively, making it difficult to utilize multi-attribute auction mechanisms.
} 
particularly the rank format over the low price format) are better at preserving the buyer-supplier relationship (e.g., minimizing opportunism suspicions, protecting overall satisfaction and future expectations) than full price visibility formats.

The potentially adverse effects of competition and the cost of evaluating the quality of each bidder bring a new dimension to the auction literature, raising the possibility that the auctioneer might wish to limit the number of bidders invited to participate. In many industries, suppliers know the number of bidders who can quote competitively. Jap (2007) finds that when the number of bidders in the auction is consistent with this number, the buyer-supplier relationship is enhanced; perhaps suppliers perceive the buyer as acting fairly, having done its due diligence in bidder selection. However, when the number of bidders is too low or too high relative to the known number of competitive bidders in the marketplace, suppliers become more negative toward the buyer. This may have implications for advertising or promotional strategies intended to attract bidders.

\section{Competition between auction hosts}

Auction hosts, auction houses, and marketplace operators, whether brick-and-mortar or online, are firms whose product is a marketplace in which buyers and sellers can transact, or a platform that connects two sides of a market. These firms act as intermediaries between buyers and sellers, similar to distribution intermediaries for fixed price goods. Most auction literature ignores the role of the auction host and considers auctions to be an interaction between the owner of an item and the bidders.

In auction markets, competition exists not only on two sides of a market but also among auction operators that provide similar services. One of the factors that determine the result of competition is network externalities. Chen et al. (2005) showed, using adaptive agent-based simulations that equilibrium exists and that a co-existence equilibrium is more likely to emerge than a monopoly equilibrium in online auction marketplaces. 
When auction marketplaces have different design features, different bidder behavior may emerge. Roth and Ockenfels (2002), for example, noted that more sniping, or last minute bidding, occurs on eBay than on Amazon. They attributed this behavior to the fixed end time on eBay relative to the soft close rule of Amazon. They showed that sniping could be in equilibrium in eBay auctions and that such an equilibrium would result in higher buyer surplus relative to a non-sniping equilibrium. Sinha and Greenleaf (2000) study the "aggressiveness” of auction bidders, a behavior related to sniping.

The conditions under which auction markets of different sizes can co-exist in equilibrium were analyzed by Ellison et al. (2004). They considered the case of sellers and buyers who choose to participate in two uniform auctions. In their two-stage game, buyers and sellers decide first on the auction market they attend. Then buyers learn their valuations and place their bids. An "efficiency effect” implies that two auction markets are less likely to co-exist when one of them is "large." However, a countervailing "market impact" determined by the effect on the clearing price of a trader switching between auctions suggests that markets of different sizes can co-exist in equilibrium.

One method auctioneers use to attract sellers is price guarantees (Greenleaf, Rao and Sinha, 1993; Greenleaf et al., 2002). Greenleaf, Rao, and Sinha (1993, hereafter GRS) developed a model of negotiations between auction houses and sellers choosing between conventional and guaranteed auctions. In a guaranteed auction, the auction house guarantees the seller a minimum amount regardless of the auction's outcome. In return, the auction house charges the seller a higher commission for any part of the auction price that exceeds the guarantee. The seller and the auction house negotiate the guarantee price and commission; the auction house sets the reserve price for the auction and retains ownership of the object if it fails to sell. The main conclusion of GRS is that guarantees make sellers better off and auction houses worse off. Greenleaf et al. (2002) show that this result is due to the seller's ability to negotiate guarantees and commissions, and not to the presence of the guarantee itself.

In the spring art auctions in 2007, Sotheby’s and Christie’s granted some of the largest guarantees ever, and this strategy proved successful in a booming art market. In the early 2000s, however, the art 
auction house Phillips was driven out of business, and forced to reorganize, when it granted excessive guarantees to attract business and many of the paintings failed to sell.

Another tool available to auctioneers is buyer's premia. Such premia in the art auction industry started at $10 \%$ in 1975 but are now at $20 \%$ for the first $\$ 500,000$ at major art auction houses, and were increased in 2007 to 25\% for the first \$20,000. Buyer’s premia can increase auction prices because many bidders do not fully weight the buyer's premium, so their perceptions of their total costs are lower, an effect observed in other applications of partitioned pricing as well (Morwitz et al. 1998).

Buy-in penalties (Greenleaf and Sinha 1996) are another practice that auction houses use to manage their relations with sellers. These penalties are an amount that the seller must pay the auction house if the auctioned property does not sell. Greenleaf and Sinha model the tradeoff between buy-in penalties and the seller's commissions that auction houses also charge. They find that auctions that use them Pareto-dominate auctions that use only sellers' commissions. The buy-in penalties motivate sellers to set lower reserve prices, which increases expected total auction revenue. This result can be used to explain why eBay and other internet auctioneers charge sellers a "Reserve Fee" (to use eBay terminology) that is refunded to the seller only if the item sells. The reserve fee is a buy-in penalty.

There are other tools available to auction houses, but an important issue is how much auction houses should spend to attract and retain buyers and sellers. This issue has been tackled by Sinha and Greenleaf (2001), and Park and Bradlow (2005). Yao and Mela (2007) find that targeting commission reductions to high value sellers increases auction house revenues.

\section{Directions and opportunities for future research}

Our discussion in this article highlights our view that competition between auctions is an important emerging area of research. Since this research is at its infancy, much remains to be done. We highlight here the most promising and most urgent directions for future research. 
We begin with technical and methodological developments that are sorely needed in auction research and conclude with opportunities for examining new data sets and addressing new problems. Methodologically, one critical need is to map the consideration set of buyers and develop similarity measures between auctions (Jank and Shmueli, 2007; Bradlow and Park, 2007; Chan et al., 2007; Haruvy and Popkowski Leszczyc, 2007a). Unlike brand choice research, where the set of competing brands under consideration is generally well-defined, with auctions it is much harder to determine what auctions the consumer is choosing between. Auctions running in parallel are not identical in object features (e.g., newness, color, memory, warranty), seller features (primarily ratings and reputation), message, auction features (opening bid, secret reserve, buy it now option, shipping, etc.), and starting and ending times. So a bidder is not likely to be evaluating all auctions in the set. Moreover, the set of close substitutes is not well defined. A distance measure, or nearness, between auctions is critical in constructing the set of auctions a bidder is choosing between. The works noted in this article and the dimensions they consider are first steps in that regard but there is still a long way to go in constructing measures and techniques for this purpose.

In statistical estimation, the need to examine auction data as a time series (as done in the various works by Jank and collaborators, Haruvy and Popkowski Leszczyc, Bradlow and Park, Park and Bradlow and Jap and Naik) and not merely as endpoints is paramount in auction research with competing auctions. With standalone auctions, one can look at the final price only and ignore the dynamics that led to it since the final price is a sufficient and relevant summary statistic of everything that happened in the auction. However, with competing auctions, a more relevant statistic would be the price relative to competing auctions at the time. Since the number and prices of competing auctions change all the time, this comparison has to be made at each point in time. The methods discussed in the papers we review here are good first steps but much more method development is needed in this regard.

Heterogeneity in bidder strategy is an important topic for future research. For example, Haruvy and Popkowski Leszczyc (2007a,b) find considerable consumer heterogeneity in search and switching 
behavior. It is important to identify the relevant consumer segments, relate each segment to a consideration set as discussed above, and identify the determinants that influence each segment's choice over auctions and the determinants influential in causing consumers in a given segment to switch to another auction.

Most empirical research on auctions today is done with eBay data which is publicly available (although eBay is making it exceedingly difficult to collect it). The topic of competition between auctions allows for the examination of such data with a fresh angle. The methodology introduced here of controlled field experiments allows the researcher to obtain such data to examine particular questions rather than searching for questions that existing data may answer. The most important dependent variable in our opinion is auction choice by consumers given the choice set, and very little is known about the determinants of such choice. Combined with the bid itself, this is a complex decision about which little is known, but for which the data are easy to collect.

The area of competition between auctions provides new data opportunities and fresh practical problems for auction researchers. One such opportunity lies in industrial auctions (section 3.1). Companies, large and small, are increasingly moving their procurement activities online and this provides many opportunities for researchers to obtain data. The formats employed in procurement auctions are sufficiently different from known formats to justify new groundbreaking research. For example, the fact that buyers typically choose the bidder who provides them the highest value rather than the bidder with the lowest price is a significant deviation from standard auction formats. The design of multi-attribute auctions, which allow a supplier's bid for a contract to be made up of several attributes, of which price is only one, will be an important area of future research. The variations on price visibility in dynamic auctions are likewise sufficiently different to warrant investigation. The works discussed in section 3.1 are just the tip of the iceberg in uncovering the numerous new formats available to procurement managers. An entire literature could emerge from this wealth of new formats. 
Competition between auction hosts (section 4) likewise provides interesting data and the investigation of such data is long overdue. The art auction market discussed in section 4 is particularly fascinating and much of the data on it can be obtained. Equally interesting is the online auction competition. While U.S. online auctions are now largely dominated by eBay (Yahoo has retired its U.S. auction site and Amazon has neglected its auctions), internationally eBay has less of a lock on the market and many markets are still fiercely contested. Within eBay, competition between formats such as between fixed price, dynamic price, or the hybrid buy-it-now option is interesting to study as are other types of format competitions mentioned in section 2.

Multiple auctions with complementarities and substitutes (2.3) are most notable in FCC spectrum auctions. Given the money involved in such auctions, the FCC is spending considerable resources on advancing research in the area. This has resulted in a large stream of research focusing on auction formats and mechanisms. Future research should also study behavioral aspects of competitive bidding in these types of auctions. Finally, research should consider the influence of the make-up of different component products on bidder's willingness to pay for bundled auctions. One interesting direction is the work by Popkowski Leszczyc, Pracejus and Shen (2008) who find that value uncertainty plays an important role in bundle valuation. Their findings show that bidders tend to use the value of certain items to infer the value of less certain items - this may result in either superadditivity or (hyper)subadditivity.

\section{Conclusions}

Auctions can no longer be viewed as isolated events that are independent of competitive forces around them, and of alternative features, formats, or venues. These competitive forces are in no way newly emerged or recognized. Two trends in recent years have brought more attention to competition between auctions. First, the emergence of larger scale auction markets has made the treatment of auctions as standalone events highly impractical and increasingly irrelevant. Second, advances in 
methodology, partly due to greater computational power, have immensely enlarged the toolkit available to the auction researcher-from advanced statistical tools-including functional data analysis, spatiotemporal models, and Bayesian methods_- to simulation studies, more powerful computational tools, broader analytical tools, and advances in experimental methods with human subjects.

It is important to stress that while we divided the topics on competition between auctions into three general sections this division is primarily for the benefit of the flow and readability of the article and is not meant to imply a real division between these issues. The considerations of one set of players are generally taken into account by another, leading to inter-dependencies between the various forms of competition. For example, the choice of auction features (e.g., secret reserve price, buy-it-now option) is critical for item competition, as it alters preferences over the items. But such choices could be an important aspect of seller competition as they pose interesting strategic choices and avenues for competition and differentiation. They are also critical issues for the auction house which determines the menu of features available to the seller, taking into consideration seller preferences, which are in turn driven by issues pertaining to seller and item competition.

While the theme of this article is that auctions cannot be viewed in isolation, the approach in many of the works we covered is to treat each feature or class of features in isolation. By necessity, sellers and auctioneers face tough choices when choosing features and strategies, and the tradeoffs and dependencies need to be carefully mapped. For example, rather than studying the effect of reputation, perhaps the correct emphasis should be on the seller's strategy in pursuing reputation. That strategy in turn may depend critically on the choice of features like shipping, insurance, etc. 


\section{References}

Anwar, S., McMillan, R. and M. Zheng (2006), "Bidding Behavior at Competing Auctions: Evidence from eBay," European Economic Review, Vol. 50 (2), February 2006, 307-322.

Bajari, P. and A. Hortaçsu (2004), “Economic Insights from Internet Auctions,” Journal of Economic Literature, XLII, 457-486

Bapna, Ravi, Wolfgang Jank, and Galit Shmueli (2006), "Price Formation and its Dynamics in Online Auctions,” forthcoming at Decision Support Systems.

Bradlow, Eric T. and Young-Hoon Park (2007), "Bayesian Estimation of Bid Sequences in Internet Auctions Using a Generalized Record Breaking Model,” Marketing Science, 26 (2), 218-229.

Carare, O. (2007) "Reserve Prices in Repeated Auctions,” mimeo, U. of Texas at Dallas

Chan, Tat Y., Vrinda Kadiyali, and Young-Hoon Park (2006), "The Exercise of Buy-It-Now Pricing in Auctions: Seller Revenue Implications,” Working Paper, Cornell University.

------------, ----------- and ----------- (2007), “Willingness to Pay and Competition in Online Auctions,” Journal of Marketing Research, 44 (2), 324-333.

Che, Yeon-Koo (1993), "Design competition through multi-dimensional auctions," RAND Journal of Economics 24 (4) 668-680.

Cox, James C., Sam Dinkin, and James T. Swarthout (2001), "Endogenous Entry and Exit in Common Value Auctions,” Experimental Economics, 4, No. 2, 163-81.

----------, Theo Offerman, Mark A. Olson, and Arthur J. H. C. Schram (2002), “Competition For Versus On The Rails: A Laboratory Experiment,” International Economic Review, 43 (3), 709-36.

Cramton, Peter, Yoav Shoham, and Richard Steinberg (2006), "Introduction to Combinatorial Auctions," in Peter Cramton, Yoav Shoham, and Richard Steinberg (eds.), Combinatorial Auctions, 1-13, MIT Press, 2006.

Dogan, K., Haruvy, E. and S. Li (2007) Social Identity in Matching Markets with Price, working paper, University of Texas at Dallas.

Donald, S.G., Harry J. Paarsch and Jacques Robert (2006), "An empirical model of the multi-unit, sequential, clock auction”, Journal of Applied Econometrics 21, 1221-1247

Ellison, Glenn, Drew Fudenberg and Markus Mobius (2004), Competing Auctions, Journal of the European Economic Association, 2(1), 30-66.

Engelbrecht-Wiggans, R. Haruvy, E. and E. Katok (2007), “A comparison of buyer-determined and price-based multi-attribute mechanisms,” Marketing Science, 26(5), 629-41.

----------- and Elena Katok (2006), "e-Sourcing in Procurement: Theory and Behavior in Reverse Auctions with Non-Competitive Contracts," Management Science 52(4), 581-596.

Goeree, Jacob K., and Charles A. Holt (2007), “A Simple Combinatorial Auction,” working paper. Greenleaf, Eric A., Ambar G. Rao, and Atanu R. Sinha (1993), "Guarantees in Auctions: The Auction House as Negotiator and Managerial Decision Maker," Management Science, 39(9), 1130-1145.

------------, Jun Ma, Wanhua Qiu, Ambar G. Rao, Atanu R. Sinha (2002), "Note on Guarantees in Auctions: The Auction House as Negotiator and Managerial Decision Maker," Management Science 48 (12), 1640-1644.

----------- and Atanu R. Sinha (1996), "Combining Buy-In Penalties with Commissions at Auction

Houses," Management Science, 42(4), 529-40.

Harris, M. and A Raviv (1981), "Allocation Mechanisms and the Design of Auctions," Econometrica, 49, 1477- 1499.

Harstad, Ronald M. (1990), “Alternative Common-Value Procedures: Revenue Comparisons with Free Entry,” Journal of Political Economy 98, 421-429.

Haruvy, E. and E. Katok (2007), “An Experimental Investigation of Buyer Determined Procurement Auctions,” working paper. 
and Peter T.L. Popkowski Leszczyc (2007a), “Consumer Optimization, Switching and

Search in Pairs of Online Auctions for Identical Items,” working paper.

and ----------- (2007b), “Individual Choice among Charity Auctions,” working paper.

and U. Unver (2007), "Equilibrium Selection in Repeated B2B Matching Markets,”

Economic Letters, 94, 284-289.

Hernando-Veciana, Ángel (2005), “Competition among auctioneers in large markets,” Journal of

Economic Theory, 121(1), 107-127

Hyde, Valerie, Wolfgang Jank, and Galit Shmueli, (2006), "Investigating Concurrency in Online

Auctions through Visualization,” The American Statistician, 60(3), 241-250.

Ivanova-Stenzel. R. and Salmon, T. (2004), "Bidder Preferences among Auction Institutions,"

Economic Inquiry, 42, 223-236.

Jank, Wolfgang and Galit Shmueli (2006), "Functional Data Analysis in Electronic Commerce

Research,” Statistical Science, 21(2), 155-166.

------------ and ------------ (2007), "Modeling Concurrency of Events in Online Auctions via Spatio-

Temporal Semiparametric Models,” Journal of the Royal Statistical Society - Series C, 56 (1), 1-27.

----------- and Shu Zhang (2007), “A comparison of concurrency models for price in online auctions,”

Working paper, Smith School, University of Maryland.

Jap, Sandy D. (2003), “An Exploratory Study of the Introduction of Online Reverse Auctions,” Journal of Marketing, 67(3), 96-107.

-- (2007), “The Impact of Online Reverse Auction Design on Buyer-Supplier Relationships,”

Journal of Marketing, 71(1), 146-59.

---------- (2002), “Online, Reverse Auctions: Issues, Themes, and Prospects for the Future,” invited

article for The Marketing Science Institute-Journal of the Academy of Marketing Science Special

Issue on Marketing to and Serving Customers Through the Internet: Conceptual Frameworks,

Practical Insights and Research Directions, Parsu Parasuraman and George Zinkhan, eds., 30(4),

506-25.

------------ and Ernan Haruvy (2007), Inter-organizational relationships and bidding behavior in

industrial online reverse auctions, working paper.

and Prasad Naik (2007), "BidAnalyzer: A Method for Estimation and Selection of Dynamic

Bidding Models,” forthcoming at Marketing Science.

Jofre-Bonet, M and Martin Pesendorfer (2003) "Estimation of a Dynamic Auction Game,"

Econometrica 71, 1443-1489

Katkar, Rama and David H. Reiley (2006), "Public Versus Secret Reserve Prices in eBay Auctions:

Results from a Pokémon Field Experiment." Advances in Economic Analysis and Policy, 6(2),

Article 7.

Klemperer, Paul (2004), Auctions: Theory and Practice, Princeton University Press

Levin, Dan and James L. Smith (1994), "Equilibrium in Auctions with Entry,” American Economic Review, 84(3), 585-99.

Lin M and Jank W (2007) "Bidder Migration in Online Auctions.” In the proceedings of the Third Symposium on Statistical Challenges in eCommerce Research (SCECR 07).

Maskin, Eric and John Riley (1984), Optimal Auctions with Risk Averse Buyers, Econometrica, 52, 1473-1518.

Matthews, T. and B. Katzman (2006), The Role of Varying Risk Attitudes in an Auction with a Buyout Option, Economic Theory, 27(3), 597-613.

McAfee, R. P. (1993), Mechanism design by competing sellers. Econometrica 61, 1281-1312.

- and Vincent, Daniel (1997), "Sequentially Optimal Auctions," Games and Economic Behavior, 18(2), 246-276

Milgrom, Paul (2007), Comment on Market Design, Stony Brook Conference, July 15, 2007, Stony

Brook. 
Milgrom, Paul (2004), Putting Auction Theory to Work, Cambridge University Press. and Robert Weber (1982), A Theory of Auctions and Competitive Bidding, Econometrica, 50 1089-1122.

Millet, Ido, Diane H Parente, John L Fizel, and Ray R Venkataraman (2004), "Metrics for Managing Online Procurement Auctions," Interfaces, 34(3), 171-79.

Morwitz, Vicki G, Eric A. Greenleaf, and Eric J. Johnson (1998), “Divide and Prosper: Consumers’

Reactions to Partitioned Prices,” Journal of Marketing Research, 35(4), 453-463.

Overby, Eric M. and Sandy D. Jap (2007), "Electronic vs. Physical Market Mechanisms: Evaluating Multiple Theories in the Wholesale Automotive Market,” working paper.

Park, Young-Hoon and Eric T. Bradlow (2005), “An Integrated Model for Bidding Behavior in Internet Auctions: Whether, Who, When, and How Much,” Journal of Marketing Research, 42(4), 470-482.

Pekec, Aleksander, Michael H. Rothkopf (2003), “Combinatorial Auction Design,” Management Science, 49(11), 1485-1503.

----------- and M. H. Rothkopf (2004), "Noncomputational Approaches to Mitigating Computational Problems in Combinatorial Auctions,” In P. Cramton, Y. Shoham, R. Steinberg (Eds.)

Combinatorial Auctions, M.I.T. Press, forthcoming.

Peters, M. A (1997), “Competitive distribution of auctions,” Review Economic Studies, 64, 97-123. Popkowski Leszczyc, Peter T.L., John W. Pracejus and Michael Shen (2008), "Why More Can Be

Less: An Inference-Based Explanation for Hyper-Subadditivity in Product Bundles,” forthcoming at Organizational Behavior and Human Decision Processes, vol. 106.

---------- and Michael H. Rothkopf (2007), “Charitable Intent and Bidding in Charity Auctions,” SSRN working paper nr. 899296.

-----------, Chun Qiu, and Yongfu He (2007), " Empirical Testing of the Reference Price Effect of Buynow Prices in Internet Auctions" SSRN working paper Nr. 689121.

Rangan, V. Kasturi (1998), “Freemarkets Online,” Boston, MA: Harvard Business School Publishing, Case \#598109, 1-20.

Reynolds, S. and J. Wooders (2007), Auctions with a Buy Price, forthcoming at Economic Theory. Riley, J.and W. Samuelson (1981) "Optimal Auctions," American Economic Review, 71, 381-392. Klemperer, Paul (2004), Auctions: Theory and Practice, Princeton University Press.

Roth, Alvin E. and Axel Ockenfels (2002) "Last-Minute Bidding and the Rules for Ending SecondPrice Auctions: Evidence from eBay and Amazon Auctions on the Internet," American Economic Review, 92(4), September 2002, 1093-1103.

Rothkopf, Michael H., and Ronald M. Harstad (1994), "On the Role of Discrete Bid Levels in Oral Auctions," European Journal of Operations Research, 74, 572-81.

-----------, Pekec, A, and Harstad, R.M. (1998), "Computationally manageable combinational auctions,” Management Science, 44(8), 1131-1147.

Sinha, Atanu R. and Eric A. Greenleaf (2000), "The Impact of Discrete Bidding and Bidder

Aggressiveness on Sellers' Strategies in Open English Auctions: Reserves and Covert Shilling," Marketing Science, 19 (Summer), 244-265.

Sun, Eric (2005), “The Effects of Auctions Parameters on Price Dispersion and Bidder Entry on eBay: A Conditional Logit Analysis,” working paper, Stanford University.

Wang, Ruqu (1993), “Auctions versus Posted-Price Selling,” The American Economic Review, 83(4), 838-851.

Wang, Shanshan, Wolfgang Jank, and Galit Shmueli (2007), "Explaining and Forecasting Online Auction Prices and their Dynamics using Functional Data Analysis,” forthcoming at Journal of Business and Economic Statistics.

-----------, Wolfgang Jank, Galit Shmueli, and Paul Smith, (2006), “Modeling Price Dynamics in eBay Auctions Using Principal Differential Analysis," forthcoming at Journal of the American Statistical Association.. 
Wilcox, Ronald (2000), "Experts and Amateurs: The Role of Experience in Internet Auctions," Marketing Letters, 11(4), 363-74.

Xie, Junjun, Terry Elrod and Peter Popkowski Leszczyc (2007), "The influence of competition on the effectiveness of seller strategy in online auctions," mimeo.

Yao, Song and Carl F. Mela (2007), “Online Auction Demand,” mimeo.

Zeithammer, Robert (2006), “Forward-looking Bidding in Internet Auctions,” Journal of Marketing Research, 43(3), 462-476.

Zeng, Daniel, James C. Cox and Moshe Dror (2007), “Coordination of Purchasing and Bidding Activities Across Posted Offer and Auction Markets,” Journal of Information Systems and eBusiness Management, 5, 25-46. 